\title{
Non-aqueous formation of the calcium carbonate polymorph vaterite: astrophysical implications
}

\author{
S. J. Day ${ }^{1,2}$, S. P. Thompson ${ }^{2}$, J. E. Parker ${ }^{2}$, and A. Evans ${ }^{1}$ \\ 1 Astrophysics Group, Keele University, Keele, Staffordshire, ST5 5BG, UK \\ e-mail: s.j.day@keele.ac.uk \\ 2 Diamond Light Source, Harwell Science and Innovation Campus, Chilton, Didcot, Oxon OX11 0QX, UK
}

Received 21 January 2013 / Accepted 13 March 2013

\begin{abstract}
Aims. We study the formation of calcium carbonate, through the solid-gas interaction of amorphous Ca-silicate with gaseous $\mathrm{CO}_{2}$, at elevated pressures, and link this to the possible presence of calcium carbonate in a number of circumstellar and planetary environments.

Methods. We use in-situ synchrotron X-ray powder diffraction to obtain detailed structural data pertaining to the formation of the crystalline calcium carbonate phase vaterite and its evolution with temperature.

Results. We found that the metastable calcium carbonate phase vaterite was formed alongside calcite, at elevated $\mathrm{CO}_{2}$ pressure, at room temperature and subsequently remained stable over a large range of temperature and pressure.

Conclusions. We report the formation of the calcium carbonate mineral vaterite whilst attempting to simulate carbonate dust grain formation in astrophysical environments. This suggests that vaterite could be a mineral component of carbonate dust and also presents a possible method of formation for vaterite and its polymorphs on planetary surfaces.
\end{abstract}

Key words. astrochemistry - methods: laboratory - planets and satellites: surfaces - dust, extinction

\section{Introduction}

\subsection{Carbonates in astrophysical environments}

On Earth, carbonates are the main constituent in chemically precipitated sedimentary rocks (e.g. limestone, dolomite) and are produced organically by marine organisms whose shells or skeletal structures are built out of calcium carbonate; however, the inorganic formation of carbonates in terrestrial environments has been found to occur exclusively through the interaction of silicate minerals with liquid water containing dissolved $\mathrm{CO}_{3}^{2-}$. However, features indicative of carbonate minerals have been detected in a wide variety of astrophysical environments, from planetary bodies within the solar system (Ehlmann et al. 2008) to dust particles surrounding stellar objects (Kemper et al. 2002; Toppani 2005; Chiavassa et al. 2005).

\subsubsection{Circumstellar Environments}

Carbonates have been detected in a number of circumstellar environments, exhibiting far-infrared (FIR) features around $62 \mu \mathrm{m}$ and $92 \mu \mathrm{m}$. The $92 \mu \mathrm{m}$ feature has been identified as calcite $\left(\mathrm{CaCO}_{3}\right)$, being the only dust species known to have a strong feature at this wavelength. Dolomite $\left(\mathrm{CaMgCO}_{3}\right)$ has a band at $\sim 62 \mu \mathrm{m}$, and has been suggested as a possible dust species; however due to other strong features of $\mathrm{H}_{2} \mathrm{O}$ and diopside $\left(\mathrm{CaMgSi}_{2} \mathrm{O}_{6}\right)$ between $62-65 \mu \mathrm{m}$ this identification is tenuous. $\mathrm{Mg}$-rich and $\mathrm{Fe}$-rich carbonates such as magnesite and siderite do not exhibit strong features in the far infrared and therefore cannot be confirmed as dust components.
Kemper et al. (2002) report the detection of carbonate features in the planetary nebulae (PNe) NGC 6302 and NGC 6537. They argue that the carbonates in these environments require formation by non-aqueous routes, such as gas-phase condensation or processes on grain surfaces. Ceccarelli et al. (2002) have also identified carbonate features in the proto-star NGC 1333 IRAS4, and they too argue for a non-aqueous origin. Chiavassa et al. (2005) have identified carbonate features in a range of pre-main sequence environments, from "Class 0" objects to Herbig AeBe stars, and identify a need for experimental evidence of non-aqueous formation mechanisms. These observations demonstrate that carbonates are present in both pre-main sequence and highly evolved environments.

A number of non-aqueous formation routes have been proposed to explain the presence of carbonates in circumstellar environments. These include: the processing of $\mathrm{CO}_{2}$-rich ices through catalytic reactions on hydrated silicate surfaces (Ceccarelli et al. 2002), direct condensation at high temperatures from gas rich in $\mathrm{CaO}$ and $\mathrm{CO}_{2}$ (Toppani 2005), and solid-gas interaction of silicate grains and hot, gaseous $\mathrm{CO}_{2}$ (Kemper et al. 2002). However, Ferrarotti \& Gail (2005) calculated that direct condensation of carbonate grains would not be viable in such environments due to the low temperature $(800 \mathrm{~K})$ required for carbonates to precipitate from the gas phase. At distances from the central star implied by these temperatures the outflowing gas would be significantly diluted, suppressing the formation of less stable dust species such as carbonates. In pre-main sequence environments carbonates could form through processing on larger planetesimals within the proto-planetary disk. Collisions of such bodies would provide a source for the carbonate dust observed in these systems. Rietmeijer et al. (2008) support the carbonate 
formation method suggested by Kemper et al. (2002). They have shown experimentally that solid, amorphous $\mathrm{CaSiO}_{3}$ can form though vapour phase condensation as a deep metastable eutectic composition. Rietmeijer et al. (2008) proposed that these amorphous, $\mathrm{Ca}$-rich silicates could then react with gaseous $\mathrm{CO}_{2}$ to produce calcium carbonate $\left(\mathrm{CaCO}_{3}\right)$ via the simple, single-step reaction:

$\mathrm{CaSiO}_{3}+\mathrm{CO}_{2} \rightarrow \mathrm{CaCO}_{3}+\mathrm{SiO}_{2}$.

Additionally, Chiavassa et al. (2005) emphasise the fact that both $\mathrm{PNe}$ and young stellar objects are known sources of X-ray emission and suggest that carbonates could form in both environments through the interaction of X-rays with water-ice on silicate dust grains, increasing the mobility of $\mathrm{H}_{2} \mathrm{O}$ close to that of liquid water.

\subsubsection{Planetary environments}

Carbonates have long been known to be present within chondritic meteorites (Rubin 1997) and have typically been used to infer the presence of liquid water. In the case of meteorites, the presence of carbonate phases is believed to be the result of aqueous alteration of silicate minerals on a larger parent body (Fredriksson \& Kerridge 1988). A variety of carbonates are known to be present on larger bodies in the solar system, primarily Mars and Venus (Ehlmann et al. 2008; Viviano et al. 2012); and in these cases their presence is also often associated with aqueous alteration during the planets' history. Mars and Venus are both known to have abundant $\mathrm{CO}_{2}$ within their atmospheres, albeit at vastly different atmospheric pressures, and it has been suggested that chemical weathering could lead to the formation of carbonates through reaction (1) (Visscher 2009). This solidgas reaction of $\mathrm{Ca}$-rich silicates with $\mathrm{CO}_{2}$ has been suggested as a possible method for regulating the atmospheric $\mathrm{CO}_{2}$ on Venus (Visscher 2009), with calcium silicates on its surface reacting with the high $\mathrm{CO}_{2}$ surface pressure of 90 bar, at a temperature of $750 \mathrm{~K}$ (Wood et al. 1968); however, this is currently a matter of debate (Treiman \& Bullock 2012) and assumes that the abundance of Ca-rich silicates exposed on the surface of Venus is sufficiently high. It has also been argued that this would not be a viable buffer of $\mathrm{CO}_{2}$ and there is doubt about the abundance of wollastonite $\left(\mathrm{CaSiO}_{3}\right)$ on the surface of Venus to allow this reaction to occur (Treiman \& Bullock 2012).

Carbonate features have also been reported on the surface of Mars using the Compact Reconnaissance Imaging Spectrometer for Mars (CRISM) on the Mars Reconnaissance Orbiter (Ehlmann et al. 2008; Viviano et al. 2012). These carbonates have been found in localised areas on Mars, with little evidence for carbonate minerals elsewhere on the surface of the planet. van Berk et al. (2012) suggests that in Mars' history the partial pressure of $\mathrm{CO}_{2}$ was much higher than it is today, and that the carbonates could have been formed through exposure to $\mathrm{CO}_{2}$ at a partial pressure of 1 bar over a long period of time $\left(>10^{4}-10^{5}\right.$ years $)$.

The Martian meteorite ALH884001 was found to contain spherical carbonate structures that, due to their well defined shape, were initially proposed as evidence for past life on Mars (McKay et al. 1996). However, an alternative interpretation proposed by Vecht \& Ireland (2000) was that the spherical features were indicative of vaterite (metastable $\mathrm{CaCO}_{3}$, see Sect. 1.2) known to grow in a distinctive spherical habitat, and although no longer of vateritic composition, they were likely formed inorganically by more stable carbonate phases pseudo-morphing an earlier vaterite assemblage.

\subsection{Vaterite}

The three predominant anhydrous calcium carbonate mineral phases are calcite, aragonite and vaterite. Of these, calcite is the most stable, with aragonite and vaterite being metastable phases, existing only under a narrow range of temperature and pressure conditions. Calcite is therefore the most abundant and as such, it is generally calcite that is attributed to carbonate features found within astrophysical environments (e.g. Ceccarelli et al. 2002; Chiavassa et al. 2005). However, vaterite has been found in a selection of enstatite achondrite meteorites (DuFresne \& Anders 1962; Okada et al. 1981; Vecht \& Ireland 2000).

Naturally forming vaterite is rarely found on Earth, predominantly occurring in association with organic tissue (Sutor \& Wooley 1969) and bacteriological biomineralisation products (e.g. Rodriguez-Navarro et al. 2003; Sachez-Moral et al. 2003; Falini et al. 2005; Cacchio et al. 2004; De Muynck et al. 2008; Chen et al. 2009; Zamarreño et al. 2009) and freshwater mollusc shells and pearls (e.g. Wehrmeister et al. 2007; Jacob et al. 2008; Soldati et al. 2008). Naturally occuring vaterite has been discovered in small amounts within zones of contact metamorphism (McConnell 1960; Kolodny \& Gross 1974), drilling mud (Friedman et al. 1993) and in stagnant, natural waters, forming as a result of spontaneous precipitation (e.g. Rowlands \& Webster 1971; Grasby 2003).

Vaterite can be inorganically synthesized in the laboratory through a number of processes, including precipitation of a calcium carbonate gel from concentrated calcium and carbonate solutions (Andreassen 2005), through the decomposition of the hydrated carbonate phase ikaite $\left(\mathrm{CaCO}_{3} \cdot 6 \mathrm{H}_{2} \mathrm{O}\right.$; Tang et al. 2009) or stabilised via biomimetic-based precipitation in the presence of organic additives (e.g. Thompson et al. 2011a,b), although these processes are often involved and, though reproducible, are often sensitive to variations in the preparation conditions. Once formed, vaterite is metastable and very soluble, more so than the calcite and aragonite polymorphs, converting into calcite in less than $25 \mathrm{~h}$ at room temperature (Silk 1970) when in contact with water. In the absence of water it has been found to transform into calcite at temperatures between $730 \mathrm{~K}$ and $840 \mathrm{~K}$ (Subba Rao 1973; Peric et al. 1996).

The crystal structure of vaterite has been studied in detail over the last few decades; however the rarity of vaterite in nature and its reluctance to form large single crystals has lead to a number of uncertainties regarding its crystallographic structure (see Table 1 for a summary). The main reports of the vaterite crystal structure come from Kamhi (1963) and Meyer (1960, 1969). Meyer (1960, 1969) suggests both a hexagonal and orthorhombic unit cell, whereas Kamhi (1963) reports a hexagonal unit cell with a prominent hexagonal pseudo-cell. These cells can be linked, and the orthorhombic cell of Meyer can be related to the hexagonal Kahmi cell via a transformation of lattice parameters (see discussion by Tang et al. 2009). More recently, LeBail et al. (2011), in an attempt to fit single-crystal data of vaterite, propose an Ama 2 space group using a model based on crystal microtwinning ( 3 orthorhombic domains rotated by $120^{\circ}$ to produce pseudohexagonal symmetry). Additionally, Mugnaioli et al. (2012) have used electron diffraction techniques, allowing the collection of diffraction data from single nanocrystals, to propose a monoclinic structure, with a $C 2 / c$ space group. However, carbonate anions in vaterite exhibit disorder such that their locations are still a matter of debate (Medeiros et al. 2007; Gebauer et al. 2009; Jacob et al. 2009; Wehrmeister et al. 2010). Density functional theory (DFT) calculation by Demichelis et al. (2012) suggest the previous Pbnm and $P_{5} 22$ structures could in fact 
Table 1. Comparison of proposed crystal structures for vaterite from the literature.

\begin{tabular}{|c|c|c|c|}
\hline Reference & Unit cell parame & $\operatorname{ters}(\AA)$ & Space grp. \\
\hline Demichelis (2012) & $a=7.12$ & $c=25.32$ & $P 3_{2} 21$ \\
\hline Mugnaioli (2012) & $17 b=7.12$ & 17 & $C 2 / c$ \\
\hline Wang \& Becker (2009) & $a=7.29 \quad b=7.29$ & $c=$ & $P 6_{5} 22$ \\
\hline Le Bail (2009) & $a=8.47 \quad b=7.16$ & $c=$ & $A m a 2$ \\
\hline Kahmi (1963) & $a=7.16$ & $c=16.98$ & $\mathrm{P}_{3} / \mathrm{mmc}$ \\
\hline Kamhi (1963) & $a^{\prime}=4.13$ & $c^{\prime}=8.49$ & $\mathrm{~Pb}_{3} / \mathrm{mmc}$ \\
\hline Meyer (1960) & $a=4.13 \quad b=7.15$ & $c=8.48$ & Pbnm \\
\hline
\end{tabular}

represent unstable transition states leading towards a more stable structure with $P 3_{2} 21$ symmetry. The DFT calculations suggest there are at least three distinct minima whose energies and activation barriers for interconversion are all within the accessible range of thermal energy at room temperature. Wang \& Becker (2009), however, suggest the $P 6_{5} 22$ space group for a stable, fully ordered vaterite structure, obtained using first principles calculations and molecular dynamic simulations. Therefore, the uncertainty surrounding the structure of vaterite observed in different experiments could be due to differing combinations of structures involving different symmetries.

In this paper we report on the formation of vaterite, through a solid-gas reaction of amorphous calcium silicate powders $\left(\mathrm{CaSiO}_{3}\right)$ and gaseous $\mathrm{CO}_{2}$ at elevated pressure (6-40 bar) and temperature $(273-1223 \mathrm{~K})$, with the intention of demonstrating how carbonate phases might form in non-aqueous astrophysical environments. We focus on carbonation of pure $\mathrm{Ca}$-silicates especially, as $\mathrm{Mg}$-rich carbonates do not fit the observed $92 \mu \mathrm{m}$ feature, indicative of carbonates, in astronomical spectra (Kemper et al. 2002).

\section{Experimental}

An amorphous calcium-rich silicate was produced via a sol gel method (described in detail by Thompson et al. 2012a), in which the metal salts $\mathrm{CaCl}_{2}$ and $\mathrm{Na}_{2} \mathrm{SiO}_{3}$ were combined in $0.1 \mathrm{M}$ solutions to form samples having the stoichiometric composition $\mathrm{CaSiO}_{3}$. In order to prevent carbonation of the final samples through the interaction with atmospheric $\mathrm{CO}_{2}$, they were stored in gel form under demineralised water until required, at which point the gels were dried in a carbolite HVT vacuum furnace $\left(P<10^{-4} \mathrm{mbar}\right)$, initially purged with nitrogen. The gels were dried at a temperature of $323 \mathrm{~K}$ for approximately $1 \mathrm{~h}$, producing very fine-grained powders (e.g. Fig. 1) with an average grain size of $<10 \mu \mathrm{m}$. Upon removal from the furnace samples were immediately stored in sealed glass vials under argon, prior to being loaded into the experimental cell.

In situ synchrotron X-ray powder diffraction (SXPD) measurements were taken on Beamline I11 (Thompson et al. 2009) at the Diamond Light Source, UK using a position sensitive detector (PSD) allowing for fast, real-time data collection (Thompson et al. 2011a). The I11 beamline receives low divergence, high intensity X-rays from a 22-pole undulator source. Monochromatic X-rays are selected by a double bounce Si(111) monochromator, coupled with double bounce harmonic rejection mirrors. The PSD comprises 18 pixellated Si strip detection modules tiled to give a $90^{\circ}$ measurement arc. The X-ray wavelength, calibrated against a NIST SRM 640c standard Si powder, was $0.825590 \AA$.

A high pressure gas cell (Thompson et al. 2012b, see Fig. 2) was used in order to expose the sample to high purity $(99.98 \%)$

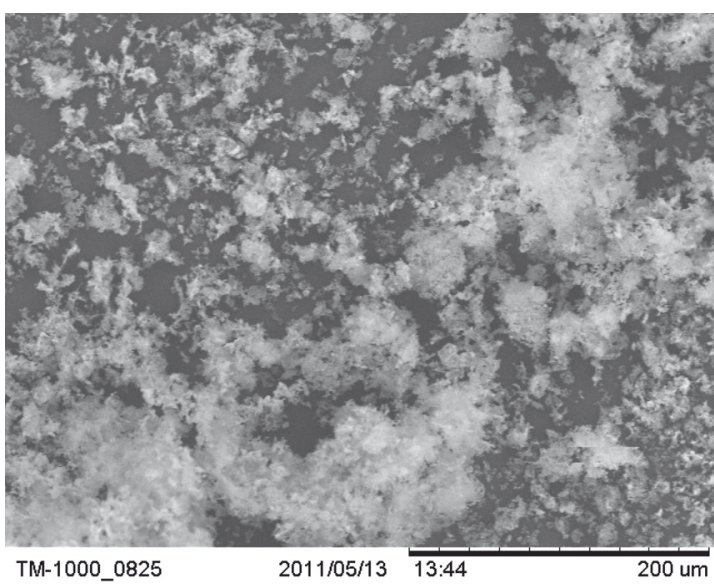

Fig. 1. Scanning electron microscope image of the final powder product with composition $\mathrm{CaSiO}_{3}$, vacuum dried at $323 \mathrm{~K}$.

$\mathrm{CO}_{2}$ at varying pressures (1-40 bar), and heating of the sample was performed using a Cyberstar hot air blower (Ramp rate: $10 \mathrm{~K} / \mathrm{min}$ up to $1273 \mathrm{~K}$ ) located beneath the sample capillary. Powder samples were loaded into $0.7 \mathrm{~mm}$ diameter quartz capillaries (maximum pressure 50 bar) or $0.79 \mathrm{~mm}$ sapphire tubes (maximum pressure 100 bar) and held in place with a quartz wool plug. It should be noted that, while the sapphire tubes are straight and have a constant diameter along their length, the quartz capillaries are tapered towards to the (closed) end of the capillary; consequently they are usually smaller than their nominal diameter. It was therefore found necessary to apply greater pressure to the powder to fill the quartz capillaries, resulting in tighter packing; as discussed below this has implications for the gas pressure required to initiate the reaction. The samples were mounted into the high pressure cell, aligned on the diffractometer and connected to the gas control system (Parker et al. 2011). Prior to connecting the sample to the system the gas supply line was pumped down to vacuum to remove air from the system and $\mathrm{CO}_{2}$ was then injected to 1 bar.

Once the sample was mounted the $\mathrm{CO}_{2}$ pressure was increased to 6 bar, to ensure adequate gas penetration through the length of the sample to position of the X-ray beam. However, due to the slightly smaller diameter of the quartz capillary and the tighter packing of the sample within the capillary, it was determined that an initial pressure of 20 bar was required in order to obtain adequate gas penetration through the sample and observe a reaction at the beam position.

Due to the tighter packing of the sample in the quartz capillaries, the gas is prevented from penetrating through the complete length of the capillary, instead reacting only with the material at the entrance to the capillary, outside of the section covered by the beam. In this case, the additional pressure required to observe a reaction when using the quartz capillary is not believed to be due to any difference in the sample but merely represents the additional pressure required to allow the gas to diffuse through the full length of the capillary. Thompson et al. (2012a) reported the carbonation of the same amorphous samples in a vacuum desiccator using ammonium carbonate as the source of $\mathrm{CO}_{2}$, supporting the fact that the need for higher pressure in this study is solely due to the experimental setup, and is not necessary for such a reaction to occur.

The sample was heated steadily from room temperature (RT; $298 \mathrm{~K}$ ) to $1223 \mathrm{~K}$ and data were collected at $5 \mathrm{~K}$ intervals. To provide sufficient powder averaging during data collection the 


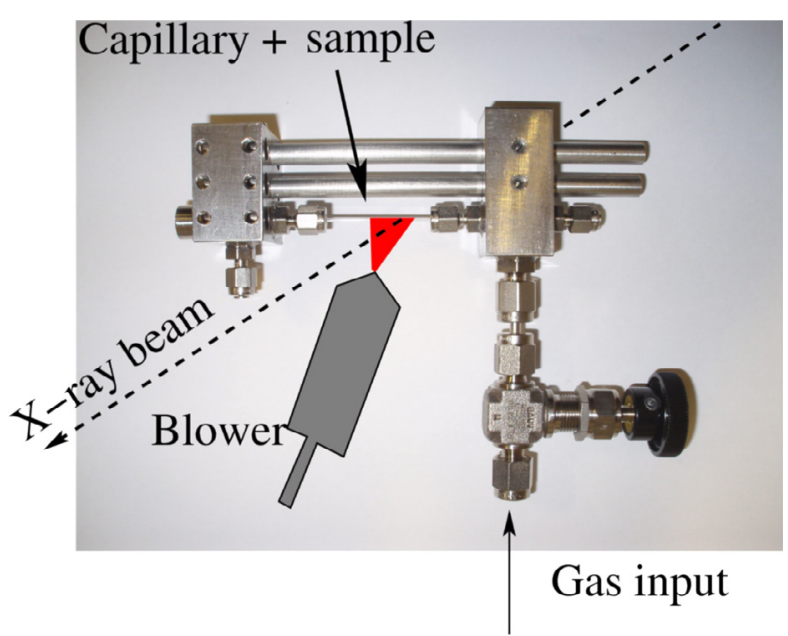

Fig. 2. High pressure gas cell with sapphire tube. X-ray beam is at a right angle to the capillary.

sample capillary was rocked $\pm 15^{\circ}$ about its length. Every scan with the PSD took $10 \mathrm{~s}$. For subsequent samples the pressure was increased at ambient temperature, in steps of 10 bar, up to a maximum pressure of 40 bar.

\section{Results}

Upon initial injection of $\mathrm{CO}_{2}$, at a pressure of 6 bar, into the larger diameter sapphire tube, the formation of a crystalline carbonate phase was observed almost instantaneously. Figure 3 shows a comparison of the initial SXPD pattern of the $\mathrm{CaSiO}_{3}$ sample under vacuum at ambient temperature and the first SXPD scan taken as the $\mathrm{CO}_{2}$ was opened to the sample. Injection of $\mathrm{CO}_{2}$ triggered the formation of a crystalline phase.

Once crystallised the sample exhibits multiple strong, wellresolved features, suggesting a well ordered crystalline structure. Peak search-match software Match! ${ }^{1}$ suggested that the pattern could be fit by a mixture of the calcium carbonate phases vaterite and calcite. The distinctive groups of features at $10^{\circ}-14.5^{\circ}$, $22^{\circ}-24^{\circ}$ and $25^{\circ}-27^{\circ} 2 \theta$ are attributed to vaterite, while the remaining features at $12.2^{\circ}, 15.8^{\circ}, 19.1^{\circ}$ and $20.9^{\circ} 2 \theta$ are due to calcite.

The pressure was held at 6 bar at RT for approximately $30 \mathrm{~min}$. During this time the structure continued to evolve, with the peaks steadily growing in intensity; this was accompanied by a slow but steady decrease in the $\mathrm{CO}_{2}$ pressure at the sample. We should note however, that we cannot rule out the presence of an amorphous silicate component remaining in the sample; evidence suggests that the amorphous silicate component anneals at higher temperatures, or after prolonged exposure $(\sim 5 \mathrm{~h})$ at $T>1220 \mathrm{~K}$ (Fabian et al. 2000).

\subsection{Thermal evolution}

Heating of the sample was initiated after $30 \mathrm{~min}$ at a pressure of 6 bar. During this time the $\mathrm{CO}_{2}$ pressure dropped steadily, an indication of the reaction still occurring, and was topped up to 6 bar when the pressure dropped below 4 bar (after approximately $2.5 \mathrm{~h}$ ). The experiment was then left to run overnight, with scans being taken at $5 \mathrm{~K}$ intervals (approximately every $3 \mathrm{~min}$ ) between RT and $1223 \mathrm{~K}$, during which the pressure had

\footnotetext{
1 Crystal Impact http://www . crystalimpact.com/match/
}

dropped and settled at 2.6 bar. The results of this are plotted in Fig. 4 presenting a selection of patterns at roughly $50 \mathrm{~K}$ increments. These show that, following the initial formation of the carbonate phases, they remain relatively stable during heating until the temperature exceeds $753 \mathrm{~K}$, at which point the carbonate phases start to break down and the sample begins to anneal, finally crystallising, at $T>1083 \mathrm{~K}$, to wollastonite $\left(\mathrm{CaSiO}_{3}\right)$. This is discussed in greater detail in Sect. 4.1.

\subsection{Pressure dependence}

Due to the strong features in the diffraction patterns caused by the use of a sapphire tube it was decided to perform further experiments using quartz-glass capillaries. As before, the sample of amorphous $\mathrm{CaSiO}_{3}$ was initially exposed to a $\mathrm{CO}_{2}$ pressure of 6 bar; however, scans indicated that no major structural changes occurred upon exposure to the gas. The pressure was held at 6 bar for $10 \mathrm{~min}$, during this time two very sharp, intense peaks appeared at $16.72^{\circ}$ and $33.32^{\circ} 2 \theta$. These correspond to Bragg reflections of calcite, however the intensities are much higher than expected, indicating insufficient powder averaging and therefore likely result from the localised carbonation of a small number of isolated particles, some of which happen to lie in the Bragg condition. As further crystallisation occurs, these particles are taken out of the Bragg condition and full crystallisation occurs at higher pressures.

The pressure was then increased to 10 bar and held for $15 \mathrm{~min}$, during which the features at $16.72^{\circ}$ and $33.32^{\circ} 2 \theta$ were observed to diminish with time. Before they disappeared completely, the pressure was increased to 20 bar. Initially, there was no observable effect on the structure; however, after approximately $15 \mathrm{~min}$ at this pressure the steady growth of multiple crystalline features, due to calcite and vaterite phases, was observed. A further increase in pressure up to 30 bar appeared to accelerate the rate of carbonation, increasing the peak intensities, but did not produce any further changes to the phase structure. Figure 5 shows a selection of SXPD patterns as a function of increasing pressure, showing the evolution of the sample.

\section{Analysis}

\subsection{Thermal evolution of $\mathrm{CaSiO}_{3}$}

Figure 6a shows the result of a Rietveld structure refinement using the TOPAS-Academic software package (Coelho 2007) and published lattice parameters for vaterite and calcite as starting values. The published lattice parameters used in the refinement were obtained from the Inorganic Crystal Structure Database (ICSD) reference database ${ }^{2}$ and are shown in Table 2 . The vaterite phase was fit with the hexagonal pseudo-cell of Kamhi (1963), with unit cell parameters of $a^{\prime}=4.13 \AA$ and $c^{\prime}=8.49 \AA$ and space group $P 6_{3} / m m c$. The reduced hexagonal cell structure was chosen over the larger hexagonal structure of Kamhi (1963; see Table 1) as it provided the best fit to our data. The modelled fit is shown in Fig. 6a along with the difference pattern between the overall fit and the measured data. The strong peak at $19.97^{\circ} 2 \theta$ is due to the sapphire capillary and has therefore been excluded from the fit. The two phase fit produced agreement factors of $R_{\mathrm{wp}}=1.78$ and $R_{\mathrm{exp}}=1.05$ with a goodness of fit $(\mathrm{GoF})$ of 1.69; the very low R-factors relate to the high background present in the data.

\footnotetext{
2 FIZ Karlsruhe http://cds.dl.ac.uk/cds/datasets/crys/ icsd/llicsd.html
} 
S. J. Day et al.: Formation of vaterite: astrophysical implications

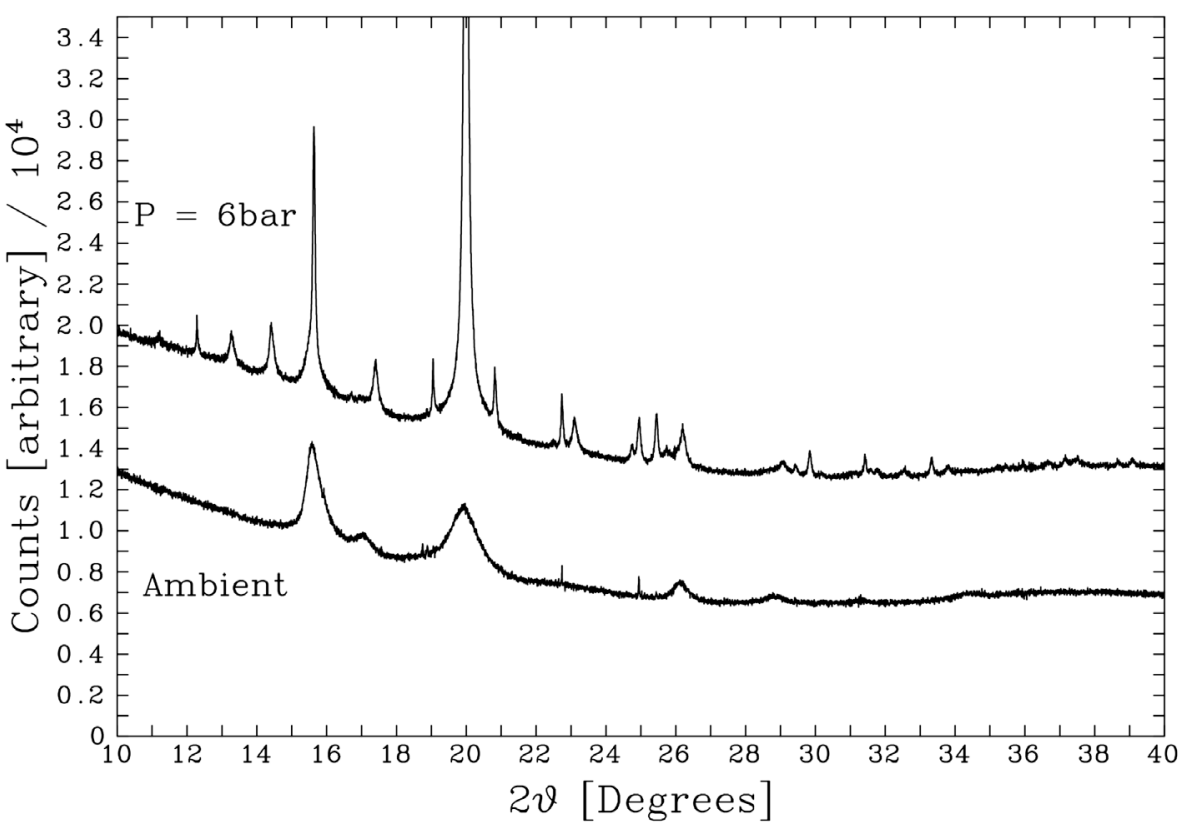

Fig. 3. A comparison of the diffraction patterns for the powdered sample of $\mathrm{CaSiO}_{3}$ before (lower curve) and after (upper curve) the injection of $\mathrm{CO}_{2}$. The strong feature at $19.97^{\circ}$ $2 \theta$ is due to the sapphire tube. Patterns are offset in the $y$-axis.

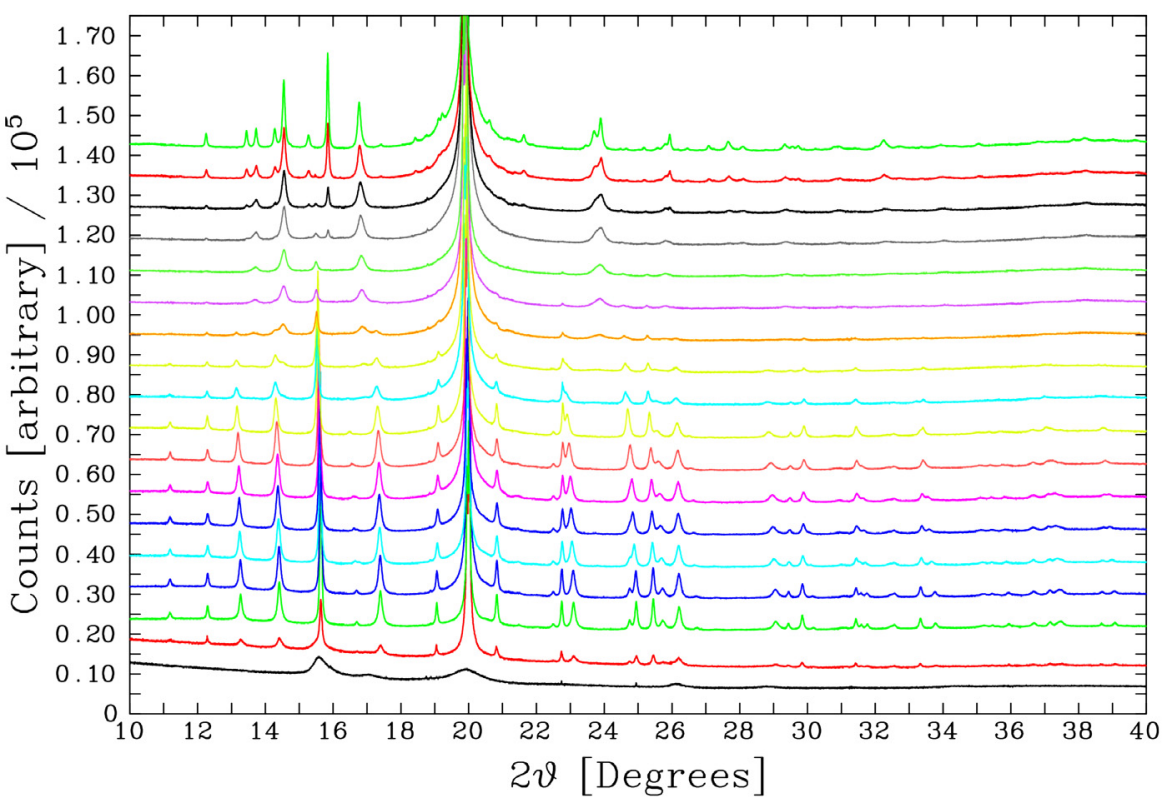

Fig. 4. Thermal evolution of $\mathrm{CaSiO}_{3}$ exposed to $\mathrm{CO}_{2}$ at 6 bar whilst being heated from room temperature (bottom scan) to $1173 \mathrm{~K}$ (top scan). Patterns have been offset on the $y$-axis for clarity and temperature is increasing in steps of $50 \mathrm{~K}$ from bottom to top. The strong feature at $19.972 \theta$ is due to the sapphire tube.
The refined lattice parameters and the calculated weight percentage of each phase are shown alongside the published values in Table 2 . The refined parameters do not differ significantly from the reference values.

Figure 7 is a plot of weight percentage against temperature for the vaterite, calcite and wollastonite phases, with values taken from a batch refinement of selected data sets at approximately $20 \mathrm{~K}$ temperature intervals. This provides a more detailed view of what is happening, with regards to composition of the sample at higher temperatures (>800 K). From this we can clearly see that, at lower temperatures, the vaterite and calcite phases remain fairly stable, with the relative weight percentage of vaterite increasing by just $3 \%$ over a period of approximately $5 \mathrm{~h}$. However, once the temperature reaches $723 \mathrm{~K}$ the percentage of vaterite begins to fall, being replaced by an increasing amount of calcite. The weight percentage of vaterite continues to fall gradually until calcite supersedes it at a temperature of $770 \mathrm{~K}$. At a temperature of $840 \mathrm{~K}$, wollastonite begins to crystallise and can be included in the fit, this phase then quickly dominates the sample as it continues to crystallise at higher temperatures. Figure 4 indicates that at a temperature of $973 \mathrm{~K}$, the carbonate peaks have almost disappeared, appearing as weak, broad features, indicating that the carbonate phases are not stable at such temperatures and have broken down, this is also evidenced in Fig. 7 as the amount of vaterite and calcite within the sample at this stage are less than $10 \%$. This leads to the sample fully annealing at a temperature of $1103 \mathrm{~K}$ to fully crystalline $\mathrm{CaSiO}_{3}$ (wollastonite). Alternatively, plotting lattice parameter $a$ against temperature for the vaterite phase indicates a slight thermal expansion between RT and $943 \mathrm{~K}$, this provides a thermal expansion coefficient of $\sim 5 \times 10^{-5} \mathrm{~K}^{-1}$ (see Fig. 8).

\section{2. $\mathrm{CaSiO}_{3}$ in quartz capillary}

The crystalline phase formed at a pressure of 20 bar on the second run was identified as also being a combination of calcite and 


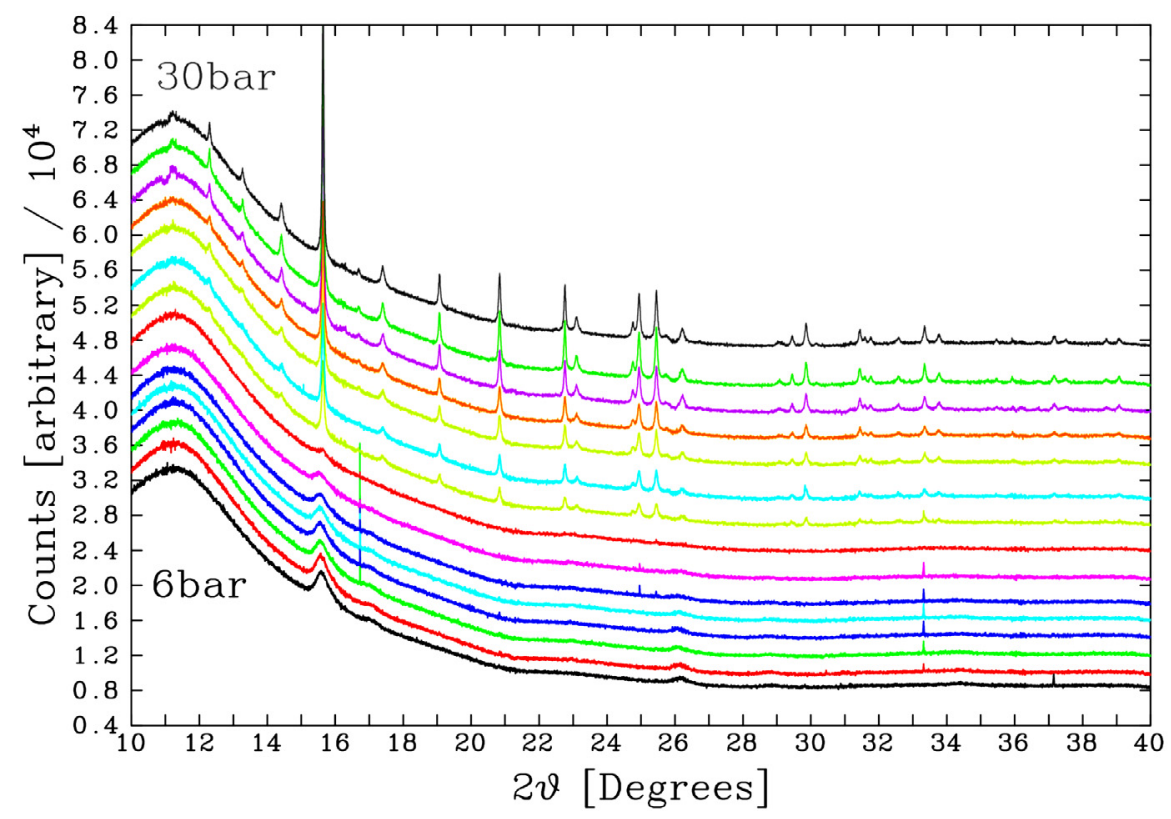

Fig. 5. Evolution of $\mathrm{CaSiO}_{3}$ in quartz capillary with increasing pressure of $\mathrm{CO}_{2}$. Patterns have been offset on the $y$-axis for clarity and high backround is due to the quartz capillary. Pressure increases upwards from 6 bar to a maximum of 30 bar.
Table 2. Published and refined lattice parameters for vaterite and calcite phases.

\begin{tabular}{|c|c|c|c|c|}
\hline \multicolumn{5}{|c|}{ Vaterite - Space group: $\mathrm{P}_{3} / \mathrm{mmc}$} \\
\hline Capillary & & $a^{\prime}(\AA)$ & $c^{\prime}(\AA)$ & Wt \% \\
\hline & Published & 4.13 & 8.49 & \\
\hline Sapphire & Refined & $4.1226(1)$ & $8.4653(3)$ & $65.5(4)$ \\
\hline Quartz & Refined & $4.1227(4)$ & $8.462(1)$ & $50.2(4)$ \\
\hline
\end{tabular}

Calcite - Space group: R-3c

\begin{tabular}{llccc}
\hline Capillary & & $a(\AA)$ & $c(\AA)$ & Wt \% \\
\hline & Published & 5.05 & 17.32 & \\
Sapphire & Refined & $4.9869(1)$ & $17.0492(4)$ & $34.4(4)$ \\
Quartz & Refined & $4.9844(4)$ & $17.058(1)$ & $49.7(4)$ \\
\hline
\end{tabular}

Notes. Published values obtained from the ICSD database. Error values stated are for the final figures. Values given are from samples at room temperature and initial formation pressure; 6 bar for sapphire, 20 bar for quartz.

vaterite. Refinement of the data using initial crystallographic parameters obtained from the ICSD database, confirmed this. A typical fit is shown in Fig. 6b with the initial and refined parameters and calculated weight percentages listed in Table 2.

The refined values are in good agreement with published values and the refined values for the sapphire capillary sample. Figure 9 shows the weight percentages of the two phases plotted against pressure and it can be concluded that once the two phases have been formed, they remain relatively stable. An increase in pressure does not appear to have a significant effect on the composition of the two phases.

\section{Discussion}

\subsection{Formation of vaterite}

As discussed in the introduction vaterite is, with respect to aragonite and calcite, the least stable of the anhydrous calcium carbonate phases. Its formation in the present study is therefore interesting, either as a possible component of dust grains, or as a possible metastable precursor phase for the calcite grain component currently attributed to the $92 \mu \mathrm{m}$ feature (Kemper et al. 2002). We have shown that the calcium carbonate phase vaterite can be formed through the solid-gas interaction of amorphous calcium-rich silicates and gaseous $\mathrm{CO}_{2}$ at an elevated pressure of 6 bar. While the kinetics of the transformation into calcium carbonate are dependent on the initial packing density of the powdered $\mathrm{CaSiO}_{3}$ sample, as discussed in Sect. 2, the selection of vaterite over the more thermodynamically stable calcite is likely to be due to material dependent factors. In the following paragraphs we draw on the results of experiments regarding vaterite formation in other fields to show that the preferential stabilisation of vaterite in the present case likely arises from the presence of $\mathrm{SiO}_{2}$ anions.

Due to its industrial and commercial potential, there is a large body of literature that shows vaterite can be stabilized (often temporarily) in the presence of various different ions or organic and inorganic additives under widely differing experimental conditions, most of which are concerned with in vitro formation (e.g. Wray \& Daniels 1957; Nassrallah-Aboukais et al. 1998; Nothig-Laslo \& Brečvić 1999; Han et al. 2006; Nebel \& Epple 2008; Wang et al. 2009; Fernandez-Daz 2010; Gomez-Morales et al. 2010), or as a post-formation coating (Vogel et al. 2009). The origin of these stabilisation effects likely lies in the fact that vaterite, aragonite and calcite all have very similar values for their free energy $(0.5-3 \mathrm{~kJ} / \mathrm{mol}$ differences; Plummer \& Busenberg 1982; Wolf et al. 1996, 2000; Baitalow et al. 1998). Relatively small changes in either the surface area (i.e. small particle size), or in the concentration of impurities, can change their stabilisation properties such that the order of their thermodynamic stabilities becomes inverted (Navrotsky 2003, 2004). Similar thermodynamic crossovers are observed for several metal oxide systems, including the $\mathrm{TiO}_{2}$ polymorphs (rutile, brookite, and anatase; Ranade et al. 2002) and the iron oxide phases (Navrotsky et al. 2008) and can mean that the least stable phases, in the present case vaterite, are often preferentially formed. However, many experimenters (see papers cited above) have reported that, although outcomes are highly reproducible, the actual outcome is also highly dependent on changes in conditions in a non-systematic way (e.g. Pai et al. 2009; Ren et al. 2009), suggesting that kinetic factors may also be important. It 
S. J. Day et al.: Formation of vaterite: astrophysical implications

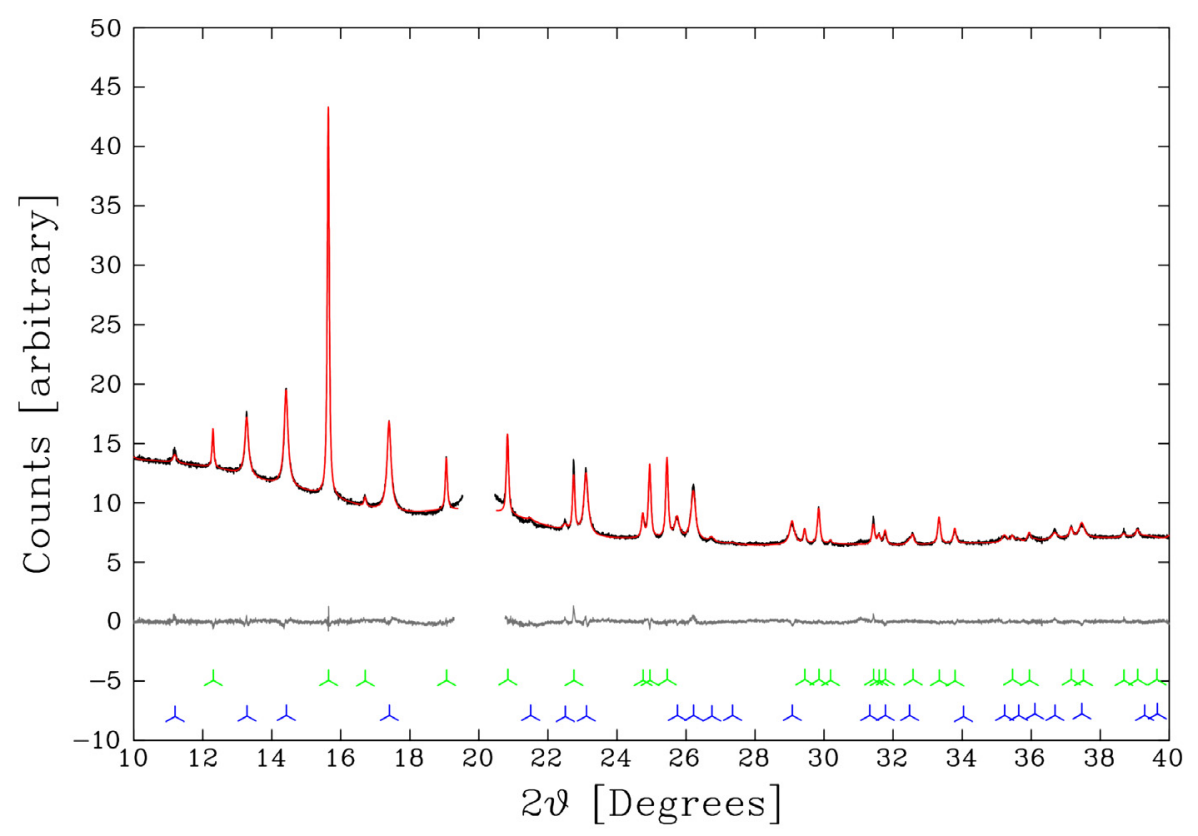

(a)

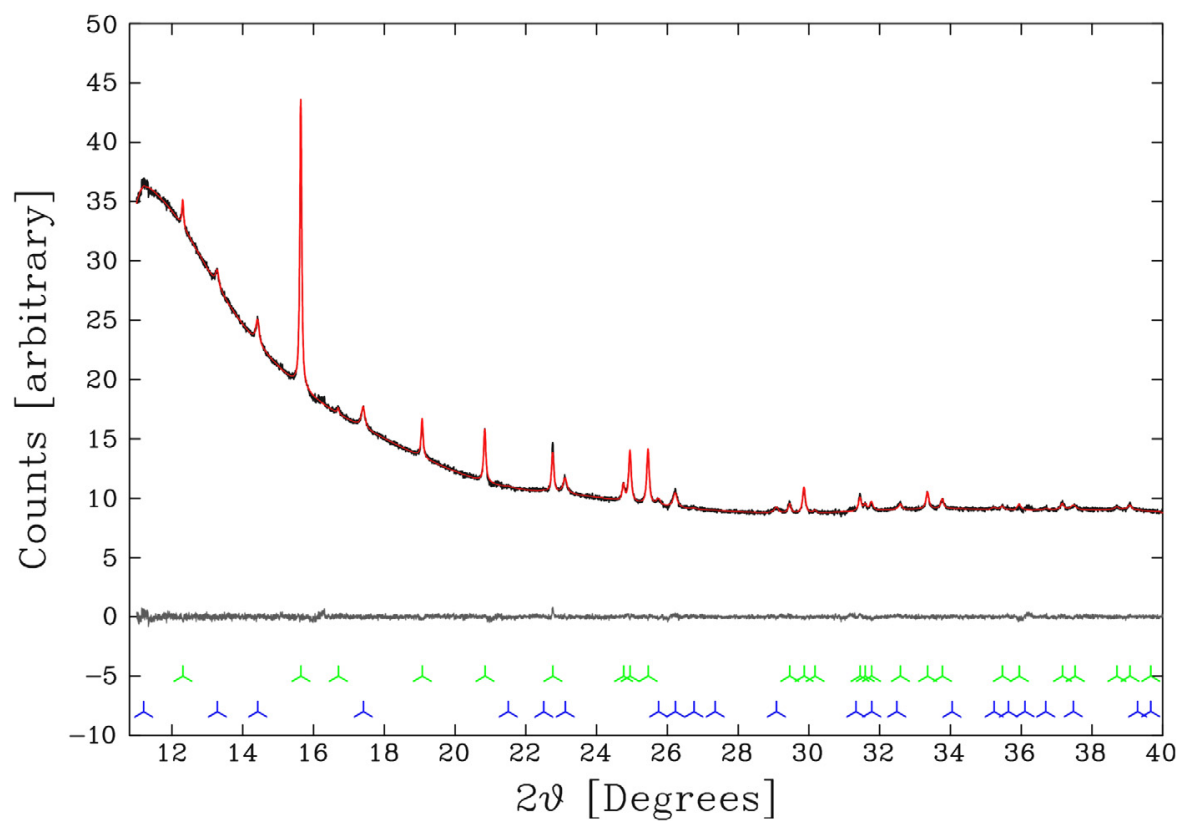

(b)
Fig. 6. Sample rietveld refinements of powder patterns exhibiting vaterite and calcite peaks. The red curves show the fit, the grey curves show the difference curve and the markers indicate the positions of the individual vaterite (blue) and calcite (green) peaks. a) Initial sample exhibiting vaterite features in sapphire capillary. The sapphire capillary exhibits a strong peak at $19.97^{\circ} 2 \theta$ which has been removed from the plot. b) Powder pattern exhibiting vaterite peaks at a $\mathrm{CO}_{2}$ pressure of 30 bar in quartz capillary. is also relevant to note Ostwald's Law of Phases, which states that, due to the lower energy barrier of more disordered states, the pathways to final crystallisation of the most stable phase will pass through all less stable phases in order of increasing stability.

For precipitating carbonates a hydrated amorphous calcium carbonate phase (ACC) acts as a precursor, which can then crystallise to a more stable form. Carbonate formation via this route is believed to follow: ACC $\rightarrow$ vaterite $\rightarrow$ aragonite $\rightarrow$ calcite (e.g. Rodriguez-Blanco et al. 2011; Bots et al. 2012, and references therein). In this instance, it is believed that due to the local coordination environment of $\mathrm{Ca}$ in the nanoframework structure of ACC being similar to those in the crystalline $\mathrm{CaCO}_{3}$ phases (Becker et al. 2003), the dehydration and condensation of the ACC structure results in the formation of vaterite without major structural rearrangements (Gebauer et al. 2010; Goodwin et al. 2010; Rodriguez-Blanco et al. 2011). In the case of carbonate formation by biomineralisation, this often occurs in the presence of silicates and Gal et al. (2010) have suggested that a mechanism of geometric frustration may operate, whereby the presence of the tetrahedral silicate ion in the flat carbonate lattice hinders the organisation of the carbonate into crystalline polymorphs; while Lakshminarayanan \& Valiyaveettil (2003) previously observed a significant expansion of the calcite lattice with added silicate anion concentration, attributing this to the incorporation of monomeric, oligomeric, and polymeric forms of silicate anion species into the calcite lattice. Such incorporations would increase the calcite lattice energy, making it less stable and therefore less favourable.

Calcium carbonate formation in the presence of various silicates and oxides was also investigated by Lin et al. (2009), who identified a correlation between the surface charge provided by the silicate/oxide and the choice of phase stabilised. 


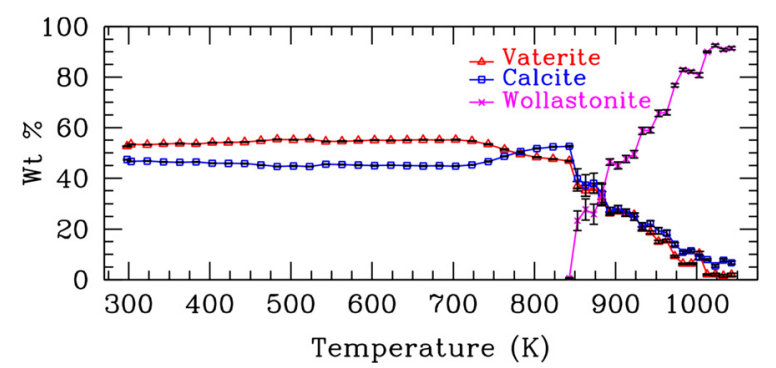

Fig. 7. Weight percentage against temperature for calcite and vaterite phases of initial $\mathrm{CaSiO}_{3}$ sample in a sapphire capillary, at a pressure of 6 bar. Where error bars are not visible they are smaller than the plotted data points.

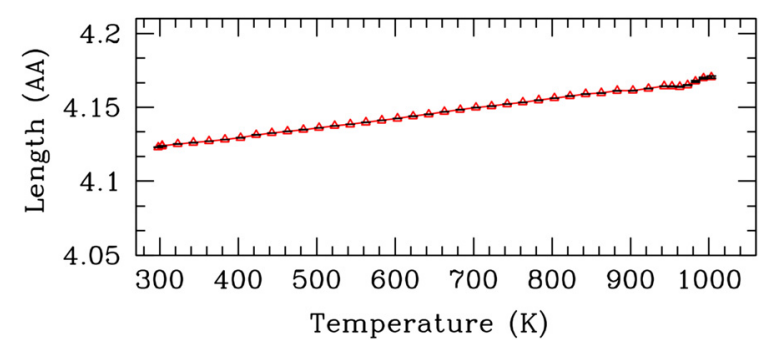

Fig. 8. The effect of temperature on lattice parameter $a$ for the vaterite phase. Sample in a sapphire capillary at a pressure of 6 bar.

Negative surface charge favoured the metastable vaterite and aragonite phases, while positive charges produced calcite. In crystalline silicates, the possible charge sites are limited by the crystal structure: planar regions which have a negative structural charge and edge regions whose charge arises from the protonation/deprotonation of surface hydroxyls at the side of stacking structures (sheets, chains etc.). Lin et al. (2009) found amorphous $\mathrm{SiO}_{2}$ did not follow the surface charge rule and always stabilised calcite. However they attributed this to the gel phase that forms when $\mathrm{SiO}_{2}$ is exposed to water, suggesting that the hydrated porous nature of the gel is not compatible with epitaxial growth and therefore no templating effect is exerted on carbonate nucleation, allowing calcite to form rather than vaterite or aragonite.

Assuming all the $\mathrm{Ca}$ atoms eventually participate in $\mathrm{CaCO}_{3}$, for carbonate formation to proceed via the gas-solid reaction in $\mathrm{CaSiO}_{3}$ necessitates the formation of $\mathrm{SiO}_{2}$, providing a free ionic species, while the absence of liquid water will negate the formation of a gel phase, allowing $\mathrm{SiO}_{2}$ tetrahedra to either be partially incorporated into the the carbonate structure, as suggested by Gal et al. (2010) and Lakshminarayanan \& Valiyaveettil (2003); or, to exert a templating surface charge effect on the forming carbonate as suggested by Lin et al. (2009). Since carbonation will occur at the Ca sites within the silicate structure, the initial small size of the carbonate could also contribute to the carbonate free energy to produce a Navrotsky stability inversion and similarly favour the stabilisation of vaterite. The fact that some calcite is also initially formed which, in the second experiment, was observed to be unstable possibly points to contributions such as particle size and remaining silicate "impurities" also influencing phase stabilisation priorities. We also acknowledge that kinetic factors may play a role in determining vaterite stabilisation and subsequent growth, particularly as our initial gas injections were performed at room temperature and relatively high gas pressures to overcome sample packing density. However these effects are

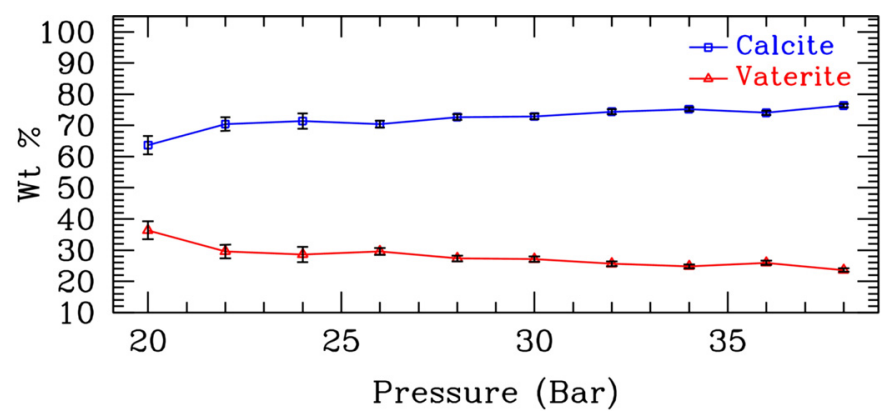

Fig. 9. Weight percentage against pressure for calcite and vaterite phases at room temperature. Initial sample of $\mathrm{CaSiO}_{3}$ in quartz glass capillary. Where error bars are not evident, they are smaller than the plotted data points.

also likely to favour the formation of disordered structures, i.e. vaterite rather than aragonite or calcite.

The vaterite formed in both cases appears to be of the same structure, both refine well using the hexagonal pseudo-cell values of Kamhi (1963). Table 2 lists the refined lattice parameters for vaterite at room temperature from both sources. The values are in good agreement with each other, suggesting that, although formed independently, the structure of the vaterite is reproducible.

\subsection{Relevance for cosmic dust}

A band near $90 \mu \mathrm{m}$ was first discovered by Kemper et al. (2002) in the spectrum of the PN NGC 6302, followed by detections in the class 0 proto-star IRAS 16293 and two HII regions (Ceccarelli et al. 2002; Takashi \& Yoko 2003); a subsequent survey of low mass proto-stars showed the feature to be common in such regions (Chiavassa et al. 2005). The circumstellar feature at $\sim 92 \mu \mathrm{m}$ was attributed by Ceccarelli et al. (2002) to calcite, who ruled out the metastable aragonite phase on the basis that its $92 \mu \mathrm{m}$ feature is too weak and that its formation nominally requires high pressures and temperatures. Whether vaterite exhibits an observable FIR feature, or indeed could be a possible candidate for the carrier of the $92 \mu \mathrm{m}$ feature, is difficult to assess. There are, to our knowledge, no published FIR spectra for vaterite (e.g. review of carbonate spectroscopy by Brusentsova et al. 2010), likely made difficult due to a combination of its low thermal stability in respect of producing polyethelene pellets and the difficulty of producing or obtaining pure specimen. However the lattice mode vibrational region is accessible by Raman spectroscopy. The Raman spectroscopic signatures of carbonates are found in three wavenumber regions: 1500-1000, 1000-500, and 500-100 $\mathrm{cm}^{-1}$ (e.g. Scheetz \& White 1977; Edwards et al. 2005). In general, bands at frequencies above $500 \mathrm{~cm}^{-1}$ are due to the internal motions of the molecular carbonate ion (internal modes), and those below $500 \mathrm{~cm}^{-1}$ are due to motions involving the entire unit cell (lattice modes). In this region the carbonate polymorphs exhibit distinct and characteristic spectral features (e.g. Edwards et al. 2005; Carteret et al. 2009). In particular vaterite exhibits a strong broad feature at $\sim 100 \mathrm{~cm}^{-1}$ and is illustrated in Fig. 10, which shows Raman spectra for a number of different vaterite samples produced via a biomimetic stabilisation process (Thompson et al. 2011a,b) that involved the hydrolysis of urea in the presence of amino acid. In these preparations varying quantities of vaterite and aragonite were precipitated along with a minor quantity of calcite. Each polytype is normally 
S. J. Day et al.: Formation of vaterite: astrophysical implications

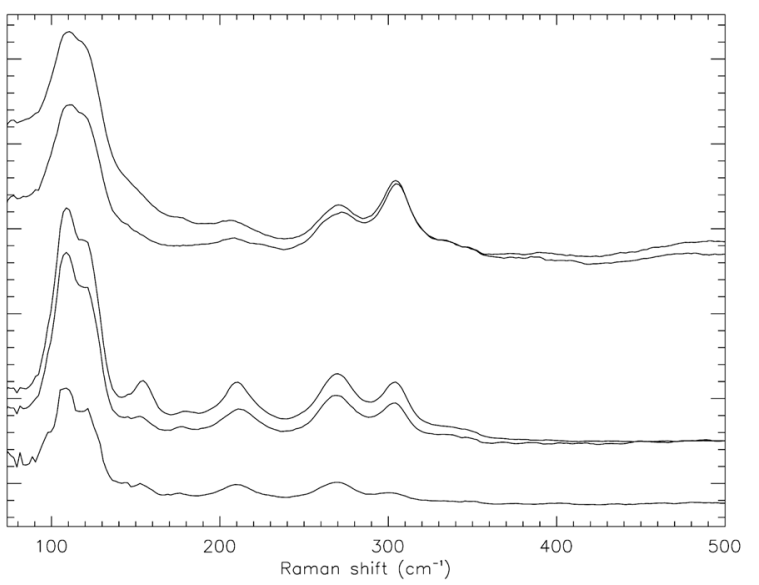

Fig. 10. Raman spectra for samples of $\mathrm{CaCO}_{3}$ vaterite produced by biomimetic synthesis, showing a strong lattice mode feature at $\sim 100 \mathrm{~cm}^{-1}$. Spectra offset in $y$-axis direction for clarity and $y$-axis scale is arbitrary.

Table 3. Factor group analysis and selection rules for calcite (after Decius \& Hexter 1977).

\begin{tabular}{lcccccc}
\hline \hline$D_{3 \mathrm{~d}}$ & $A_{1 \mathrm{~g}}$ & $A_{2 \mathrm{~g}}$ & $E_{\mathrm{g}}$ & $A_{1 \mathrm{u}}$ & $A_{2 \mathrm{u}}$ & $E_{\mathrm{u}}$ \\
\hline $\mathrm{Ca} 2 b$ & 0 & 0 & 0 & 1 & 1 & 2 \\
$\mathrm{C} 2 a$ & 0 & 1 & 1 & 0 & 1 & 1 \\
$\mathrm{O} 6 e$ & 1 & 2 & 3 & 1 & 2 & 3 \\
\hline$N_{\mathrm{T}}$ & 1 & 3 & 4 & 2 & 4 & 6 \\
$T_{\mathrm{A}}$ & & & & 0 & 1 & 1 \\
$T$ & 0 & 1 & 1 & 1 & 1 & 2 \\
$R$ & 0 & 1 & 1 & 0 & 1 & 1 \\
$\Gamma^{\text {vib }}$ & 1 & 1 & 2 & 1 & 1 & 2 \\
\hline Activity & Raman & Raman & & IR & IR \\
\hline
\end{tabular}

Notes. $N_{\mathrm{T}}=$ Total number of unit cell modes; $T_{\mathrm{A}}=$ acoustic branch modes; $T=$ optic branch translatory modes; $R=$ librational modes; $\Gamma^{\mathrm{vib}}=$ internal modes.

distinguishable by its crystal morphology: needles for aragonite, cubes for calcite and spherules for vaterite. For the amino acid, leucine, aragonite exhibited as splintered or branched needles, calcite as stepped/intersecting cuboids and vaterite as flower-like platelets. By focussing the laser spot on the different morphological structures, pure-phase Raman spectra were obtained (Horiba LamRam 800, $532 \mathrm{~nm}$ NdYAG laser, 600 line grating, 10× objective). In the figure, spectra are shown for five samples precipitated under differing conditions. As can be seen in Fig. 10, the Raman spectra for these vaterites show a strong feature in the region of $110 \mathrm{~cm}^{-1}(\sim 91 \mu \mathrm{m})$.

The lattice-mode assignment for calcite is well established (Decius \& Hexter 1977) with the selection rules shown in Table 3. The coupling which leads to factor-group selection rules is relatively weak such that lattice modes of a given basic origin (e.g. libratory) will be found in similar positions in both IR and Raman spectra (Adams \& Williams 1980). In addition, structural disorder, which shows up as broadening of Raman feature widths in the lattice mode region, is a symmetry reducing effect which can in principle lead to a relaxation of the Raman and IR activity selection rules such that certain bands can become both IR and Raman active (e.g. White 2005; Hernández et al. 1997; Duley et al. 2005; Hopkinson et al. 2008; Abe \& Shigenari 2011). In the case of vaterite, the uncertainty regarding its unit cell structure and the level of disorder make factor group analysis
Table 4. Factor group analysis and selection rules for vaterite lattice modes (after Anderson \& Brečević 1991).

\begin{tabular}{lccccc}
\hline \hline & $A_{2 \mathrm{u}}$ & $E_{1 \mathrm{u}}$ & $A_{1 \mathrm{~g}}$ & $E_{1 \mathrm{~g}}$ & $E_{2 \mathrm{~g}}$ \\
\hline$\Gamma^{\text {vib }}$ & 1 & 4 & 2 & 2 & 4 \\
$R$ & 1 & 2 & 1 & 4 & 2 \\
Activity & IR & IR & Raman & Raman & Raman \\
\hline
\end{tabular}

Notes. $R=$ librational modes; $\Gamma^{\mathrm{vib}}\left(=\Gamma_{\mathrm{Ca}}^{\mathrm{vib}}+\Gamma_{\mathrm{CO}_{3}}^{\mathrm{vib}}\right)=$ internal modes.

less certain. However, using the Meyer (1969) $P 6_{3} / m m c$ space group, Anderson \& Brečević (1991) identified the selection rules listed in Table 4 which suggests there are eight IR active and 15 Raman active vaterite lattice modes. Based on assignments to measured bands observed at higher frequencies Anderson and Brečević predict three IR active bands (corresponding to librations $A_{2 \mathrm{u}}+2 E_{1 \mathrm{u}}$ ) should lie below $200 \mathrm{~cm}^{-1}$.

Although none of the forgoing is a "proof-positive" argument that vaterite possesses a FIR band near $92 \mu \mathrm{m}$, it does suggest that measurement of vaterite in the FIR should be addressed as a matter of priority, particularly as the disorder inherent in the vaterite structure might also provide a natural mechanism to account for the observed variations in the carbonate feature width and position.

Although the operational pressures required for the present work arise from the need to provide adequate diffusion of $\mathrm{CO}_{2}$ along the length of the sample capillary, we believe similar interactions involving silicates in circumstellar outflows could occur at much lower pressures. However, even if this is not the case the formation of carbonate via this route may still be directly relevant to proto-stellar and proto-planetary envionments, where carbonates formed at higher pressure on, or in, planetesimal objects could be released as dust grains via disruptive collisional events.

\section{Conclusions}

We have observed the formation of the rare calcium carbonate polymorph vaterite through the solid-gas interaction of amorphous silicates, produced as cosmic dust analogues, and gaseous $\mathrm{CO}_{2}$ at pressures $>6$ bar. In situ synchrotron X-ray powder diffraction was used to observe the structural evolution of the material during its formation and subsequent heating to a temperature of $1173 \mathrm{~K}$. We determined a range of stability between 6-30 bar and 298-923 K, a much wider range than previously seen for vaterite. This has relevance to the surface compositions of Venus and ancient Mars (van Berk et al. 2012), where the $\mathrm{CO}_{2}$ pressure at the surface is sufficiently high for this kind of reaction to occur. Vaterite has been regarded as important due to the fact that it is rarely formed naturally and therefore its presence is usually taken as being indicative of biogenic processes.

Our alternative, inorganic method provides evidence that vaterite found in Martian meteorites and on the surface of Venus and Mars are not necessarily proof of bioactivity but could have formed naturally through a processes similar to those that we describe here.

Acknowledgements. The authors would like to thank Prof. Chiu Tang and Mr Jonathan Potter for assistance on the I11 beamline. We thank Dr. J. Nuth for helpful comments on an earlier version of this paper. This work was supported by the Diamond Light Source through beamtime award ee-6515. SJD acknowledges financial support from Diamond Light Source and Keele University. 


\section{References}

Abe, K., \& Shigenari, T. 2011, J. Chem. Phys., 134, 104506

Adams, D., \& Williams, A. D. 1980, J. Chem. Soc., Dalton Trans., 1482

Anderson, F. A., \& Brečević, L. 1991, Acta Chem. Scand., 45, 1018

Andreassen, J. P. 2005, J. Cryst. Growth, 274, 256

Baitalow, F., Wolf, G., \& Schmidt, H.-G. 1998, J. Therm. Analysis, 52, 5

Becker, A., Bismayer, U., Epple, M., et al. 2003, Dalton Trans., 551

Bots, P., Benning, L. G., Rodriguez-Blanco, J.-D., Roncal-Herrero, T., \& Shaw, S. 2012, Cryst. Growth Des., 12, 3806

Brusentsova, T. N., Peale, R. E., Maukonen, D., et al. 2010, Am. Mineral., 95, 1515

Cacchio, P., Contento, R., Ercole, C., et al. 2004, Geomicrobiology, 21, 497

Carteret, C., Dandeu, A., Moussaoui, S., et al. 2009, Cryst. Growth Des., 9, 807

Ceccarelli, C., Caux, E., Tielens, A. G. G. M., et al. 2002, A\&A, 395, L29

Chen, L., Shen, Y., Xie, A., et al. 2009, Cryst. Growth Des., 9, 743

Chiavassa, A., Ceccarelli, C., \& Tielens, A. 2005, A\&A, 432, 547

Coelho, A. 2007, TOPAS-Academic (Computer Software), version 4.1

De Muynck, W., Debrouwer, D., De Belie, N., \& Verstaete, W. 2008, Cement Concrete Res., 38, 1005

Decius, J. C., \& Hexter, R. M. 1977, Molecular Vibrations in Crystals (New York: McGraw-Hill), 241

Demichelis, R., Raiteri, P., Gale, J., \& Roberto, D. 2012, Cryst. Eng. Comm., 14, 44

DuFresne, E. R., \& Anders, A. 1962, Geochim. Cosmochim. Acta, 26, 251

Duley, W., Lazarev, S., \& Scaott, A. 2005, ApJ, 620, L135

Edwards, H. G. M., Jorge Villar, S. E., Jehlicka, J., \& Munshi, T. 2005, Spectrochim. Acta A, 61, 2273

Ehlmann, B. L., Mustard, J. F., Murchie, S. L., et al. 2008, Science, 322, 1828

Fabian, D., Jäger, C., Henning, T., Dorschner, J., \& Mutschke, H. 2000, A\&A, 364,282

Falini, G., Fermani, S., Vanzo, S., Miletic, M., \& Zaffino, G. 2005, Eur. Jour.. Organ. Chem., 1, 162

Fernandez-Daz, L. 2010, Geochimi. Cosmochimi. Acta, 74, 60646076

Ferrarotti, A., \& Gail, H.-P. 2005, A\&A, 430, 959

Fredriksson, K., \& Kerridge, J. F. 1988, Meteoritics, 23, 35

Friedman, G., Schultz, D., Guo, B., \& Sanders, J. 1993, J. Sediment. Petrol., 63, 663

Gal, A., Weiner, S., \& Addadi, L. 2010, J. Am. Chem. Soc., 132, 13208

Gebauer, D., Verch, A., Borner, H. G., \& Colfen, H. 2009, JCryst. Growth Des., 9, 2398

Gebauer, D., Gunawidjaja, P. N., Ko, J. Y. P., et al. 2010, Angew. Chem. Int. Ed., 49,8889

Gomez-Morales, J., Hernandez-Hernandez, A., Sazaki, G., \& Garcia-Ruiz, J. M. 2010, Cryst. Growth Des., 10, 963

Goodwin, A. L., Michel, F. M., Phillips, B. L., et al. 2010, J. Chem. Mater., 22, 3197

Grasby, S. 2003, Geochim. Cosmochim. Acta, 67, 1659

Han, Y. S., Hadiko, G., Fuli, M., \& Takahashi, M. 2006, J. Cryst. Growth, 289, 269

Hernández, V., Berlin, A., Zotti, G., \& Lõpez Navarrete, J. T. 1997, J. Raman Spec., 28,855

Hopkinson, H., Rutt, K., \& Cressey, G. 2008, J. Geol., 116, 387

Jacob, D. E., Soldati, A. L., Wirth, R., et al. 2008, Geochim. Cosmochim. Acta, 72,5401

Jacob, D. E., Wehrmeister, U., Soldati, A. L., \& Hofmeister, W. 2009, Geophys. Res. Abstr., 11, 11969

Kamhi, S. 1963, Acta Cryst., 16, 770

Kemper, F., Jager, C., \& Waters, L. 2002, Nature, 415, 295

Kolodny, Y., \& Gross, S. 1974, J. Geol., 82, 489

Lakshminarayanan, R., \& Valiyaveettil, S. 2003, Cryst. Growth Des., 3, 611

LeBail, A., Ouhenia, S., \& Chateigner, D. 2011, Powder Diffraction, 26, 16

Lin, Y., Hu, Q., Chen, J., Ji, J., \& Teng, H. 2009, Cryst. Growth Des., 9, 4634

McConnell, J. 1960, Mineral Mag., 32, 535

McKay, D. S., Gibson, E. K., Thomas-Keprta, K. L., Vali, H., \& Romanek, C. S. 1996, Science, 273, 924

Medeiros, S. K., Albuquerque, E. L., Maia, F. F. J., Caetano, E. W. S., \& Freire, V. N. 2007, Chem. Phys. Lett., 435, 5964
Meyer, H.-R. 1960, Fortschr. Mineral., 38, 186

Meyer, H.-R. 1969, Z. Kristallogr., 128, 183

Mugnaioli, E., Andrusenko, I., Schuler, T., et al. 2012, Angew. Chem. Int. Ed., 51,1

Nassrallah-Aboukais, N., Boughriet, A., Gengembre, L., \& Aboukais, A. 1998, J. Chem. Soc., 94, 2399

Navrotsky, A. 2003, Geochem. Trans., 4, 34

Navrotsky, A. 2004, Proc. Natl. Acad. Sci., 101, 12096

Navrotsky, A., Mazeina, L., \& Majzlan, J. 2008, Science, 319, 1635

Nebel, H., \& Epple, M. 2008, Z. Anorg. Allg. Chem., 634, 1439

Nothig-Laslo, V., \& Brečvić, L. 1999, Phys. Chem. Chem. Phys., 1, 3697

Okada, A., Keil, K., \& Taylor, G. J. 1981, Meteoritics, 16, 141

Pai, R. K., Jansson, K., \& Hedin, N. 2009, Cryst. Growth DEs., 9, 4581

Parker, J. E., Potter, J., Thompson, S. P., Lennie, A., \& Tang, C. C. 2011, Materials Sci. Forum, 706, 1707

Peric, J., Vucak, M., Krstulovic, R., Brecevic, L., \& Kralj, D. 1996, Thermochim. Acta, 277, 175

Plummer, L. N., \& Busenberg, E. 1982, Geochim. Cosmochim. Acta, 46, 1011

Ranade, M. R., Navrotsky, A., Zhang, H. Z., et al. 2002, Proc. Natl. Acad. Sci., 99,6476

Ren, F., Wan, X., Ma, Z., \& Su, J. 2009, Mater. Chem. Phys., 114, 367

Rietmeijer, F. J. M., Pun, A., Kimura, Y., \& Nuth III, J. 2008, Icarus, 195, 493

Rodriguez-Blanco, J. D., Shaw, S., \& Benning, L. G. 2011, Nanoscale, 3, 265
Rodriguez-Navarro, C., Rodriguez-Gallego, M., Chekroun, K. B., \& Gonzalez-Munoz, M. T. 2003, Appl. Environ. Microbiol., 69, 2182

Rowlands, D., \& Webster, R. 1971, Nat. Physical Sci., 229, 158

Rubin, A. E. 1997, Meteor. Planet. Sci., 32, 231

Sachez-Moral, S., Canaveras, J. C., Laiz, L., et al. 2003, Geomicrobiol., 20, 491

Scheetz, B., \& White, W. B. 1977, Am. Mineral., 62, 36

Silk, S. T. 1970, Ph.D. Thesis, New York University

Soldati, A. L., Jacob, D. E., Wehrmeister, U., \& Hofmeister, W. 2008, Mineralogical Mag., 72, 579

Subba Rao, M. 1973, Bull. Chem. Soc. Japan, 46, 1414

Sutor, D. J., \& Wooley, S. E. 1969, Gut, 10, 681

Takashi, O., \& Yoko, O. 2003, ApJ, 872, 877

Tang, C. C., Thompson, S. P., Parker, J. E., et al. 2009, J. Appl. Cryst., 42, 225

Thompson, S., Day, S., Evans, A., \& Parker, J. 2012a, J. Non-Cryst. Solids, 358, 885

Thompson, S., Day, S., Parker, J., Evans, A., \& Tang, C. 2012b, Proc. on the European Conference on Laboratory Astrophysics, eds. C. Stehl, C. Joblin, \& L. d'Hendecourt, EAS Pub. Ser., 58

Thompson, S., Parker, J., Potter, J., et al. 2009, Rev. Sci. Instrum., 80, 075107

Thompson, S., Parker, J., Marchal, J., et al. 2011a, J. Synchrotron Radiat., 18, 637

Thompson, S., Parker, J., Street, S., \& Tang, C. 2011b, J. Phys. Conf. Ser., 286, 012030

Toppani, A. 2005, Nature Letts., 437, 1121

Treiman, A. H., \& Bullock, M. A. 2012, Icarus, 217, 534

van Berk, W., Yunjiao, F., \& Ilger, J. M. 2012, J. Geophys. Res., 117, E10008

Vecht, A., \& Ireland, T. 2000, Geochim. Cosmochim. Acta, 64, 2719

Visscher, C. 2009, Geochim. Cosmochim. Acta, 64, 2719

Viviano, C. E., Moersch, J. E., \& McSween, A. Y. 2012, 43rd Lunar and Plan. Sci. Conf., 2682

Vogel, R., Persson, M., Feng, C., et al. 2009, Langmuir, 25, 11672

Wang, J., \& Becker, U. 2009, Am. Mineral., 94, 380

Wang, X. Q., Kong, R., Pan, X. X., et al. 2009, J. Phys. Chem. B, 113, 8975

Wehrmeister, U., Jacob, D. E., Soldati, A. L., Hager, T., \& Hofmeister, W. 2007, J. Gemmology, 30, 399

Wehrmeister, U., Soldati, A. L., Jacob, D. E., Hager, T., \& Hofmeister, W. 2010, J. Raman Spec., 41, 193

White, W. B. 2005, J. Ceram. Proc. Res., 6, 1

Wolf, G., Lercher, J., Schmidt, H.-G., et al. 1996, J. Therm. Analysis, 46, 353

Wolf, G., Konigsberger, E., Schmidt, H.-G., Konigsberger, L.-C., \& Gamsjager, H. 2000, J. Therm. Analysis Calorim., 60, 463

Wood, A. T., Wattson, R. B., \& Pollack, J. B. 1968, Science, 162, 114

Wray, J. L., \& Daniels, F. 1957, J. Am. Chem. Soc., 79, 203

Zamarreño, D. V., Inkpen, R., \& May, E. 2009, Appl. Environ. Microbiol., 75, 5981 